\title{
Built Environment, Transport, and COVID-19: a Review
}

\author{
David Rojas-Rueda $^{1}$ (D) $\cdot$ Emily Morales-Zamora ${ }^{2}$ \\ Accepted: 23 February 2021 / Published online: 5 March 2021 \\ (C) The Author(s), under exclusive licence to Springer Nature Switzerland AG 2021
}

\begin{abstract}
Purpose of Review The COVID-19 pandemic has impacted daily-life activities around the world. Multiple countries and cities are implementing different mitigation strategies to reduce their transmission (e.g., physical distancing, stay-at-home orders, avoiding large gatherings). Such interventions have been related to positive and negative health externalities. Currently, the selection of mitigation strategies has not been systematically considering a long-term vision for urban health equity. This review presents evidence and a framework linking COVID-19 mitigation strategies, the built environment, and transport to health determinants and outcomes. In addition, the paper provides a set of urban interventions aimed at supporting COVID-19 mitigation strategies and promoting a long-term health equity vision.

Recent Findings COVID-19 mitigation strategies, in addition to helping reduce disease transmission, have also decreased urban road transport, resulting in indirect benefits on air quality, traffic noise, and traffic incidents. On the other hand, the same mitigation strategies have had negative impacts on physical activity, mental health, home isolation, and access to transport options, among others. COVID-19 mitigation strategies are an opportunity to test and implement built environment and transport interventions aimed to maximize health equity and minimize health risks. National and local authorities should systematically integrate a long-term urban health equity vision when designing and implementing COVID-19 mitigation strategies.

Summary COVID-19 offers an opportunity to rethink the built environment and transport infrastructure with the aim to support short-term mitigation strategies and reduce long-term urban health inequities.
\end{abstract}

Keywords COVID-19 $\cdot$ Built environment $\cdot$ Transport $\cdot$ Equity $\cdot$ Environmental health

\section{Introduction}

The coronavirus disease 2019 (COVID-19) was declared a pandemic on March 11, 2020, and has impacted daily life activities around the world [1]. Multiple countries, regions, and cities are implementing mitigation strategies to reduce COVID-19 transmission (e.g., physical distancing, stay-athome orders, avoiding large gatherings). By January 2021,

This article is part of the Topical Collection on Built Environment and Health

David Rojas-Rueda

David.Rojas@colostate.edu

1 Department of Environmental and Radiological Health Sciences, Colorado State University, Environmental Health Building, 1601 Campus Delivery, Fort Collins, CO 80523, USA

2 Logan Simpson, 213 Linden Street, Fort Collins, CO 80524, USA no treatment was available to cure the virus, and while several vaccines were distributed to contain the disease, uncertainty remains about the effectiveness of immunization programs (e.g., duration of immunity, impact on transmission, the effect on new virus variants, vaccine availability, and acceptance, or capacity to achieve herd immunity) [2-4]. Based on these challenges, mitigation strategies have been suggested as one of the best tools to contain the virus globally [5-9].

Mitigation strategies have been of particular importance for vulnerable groups, such as the elderly, people with underlying health conditions, homeless or under-housed groups, and socially deprived communities, who have been reported to be more impacted by the pandemic [10-12]. Besides helping reduce disease transmission, mitigation strategies have also decreased urban road transport $[13,14]$, resulting in indirect benefits on air quality, traffic noise, and traffic incidents [15, 16]. On the other hand, the same mitigation strategies have had negative impacts on access to public spaces (e.g., parks), resulting in fewer physical activity opportunities, isolation, and mental health [14]. 
Local and national stakeholders have implemented different types of COVID-19 mitigation strategies. To our knowledge, the mitigation strategy selection and implementation have not systematically considered urban health equity with a long-term vision. The aim of this review is to present the evidence linking COVID-19 mitigation strategies with urban health determinants and outcomes, highlighting a set of built environment and transport interventions that could support current responses to COVID-19 with a long-term health equity vision.

\section{COVID-19 Mitigation Strategies}

COVID-19 mitigation strategies are non-pharmaceutical, targeted community interventions aimed at slowing the disease transmission and particularly protecting individuals at increased risk as well as healthcare and critical infrastructure workers [5-7, 9, 17]. Mitigation strategies are designed to respond when there is evidence of COVID-19 community transmission [11]. Community mitigation strategies examples are social (physical) distancing, using face coverings, avoiding large gatherings, travel restrictions, home quarantine, and clear communication from health authorities [6]. Evidence from Wuhan, China, has shown the importance of mitigation strategies, estimating that, in April 2020, implemented strategies were able to reduce more than $92 \%$ of infections [18].

\section{Urban Health Externalities From COVID-19 Mitigation Strategies}

COVID-19 mitigation strategies have resulted in transport and public space restrictions, impacting health determinants and outcomes, particularly affecting vulnerable groups and essential workers [12]. Smartphone data from applications such as Apple Maps and Google Maps have suggested that COVID19 mitigation strategies have significantly reduced urban mobility $[13,14]$. In particular, Apple Maps mobile trends reported a $64 \%$ reduction in car indication requests in 63 countries by April 20, compared to January 13, 2020 (Fig. 1) [13]. Additionally, Google Maps mobility patterns to destinations reported a $48 \%$ average reduction in "parks" visits in 131 countries in April 2020, compared to the median value from January 3 to February 5, 2020 (Fig. 1) [14].

Motorized traffic reductions among countries have resulted in air quality improvements [15]. A recent study using satellite data has suggested a $40 \%$ nitrogen dioxide $\left(\mathrm{NO}_{2}\right)$ decrease in Chinese cities between January and April 2020 compared to the same period in 2019 [19]. The same study suggested a $\mathrm{NO}_{2}$ range reduction between 20 and $38 \%$ in Western Europe and the USA [19]. Another study has reported as much as $60 \%$ reductions in surface particulate matter less than
$2.5 \mu \mathrm{m}$ of diameter $\left(\mathrm{PM}_{2.5}\right)$ and $\mathrm{NO}_{2}$ concentrations in northern China in January 2020, compared to January 2019 [20]. The U.S. National Aeronautics and Space Administration (NASA) published satellite images of air quality changes across the globe, highlighting the differences in the tropospheric $\mathrm{NO}_{2}$ column between March-April 2020 vs. the average of 2017-2019 of the same period (Fig. 2 shows the example of $\mathrm{NO}_{2}$ changes in the Indian subcontinent) [21]. In addition, a recent study has also suggested an association between long-term exposure to $\mathrm{PM}_{2.5}$ and COVID-19 mortality [22]. This study reported an increase of $8 \%$ in the COVID-19 death rate with each increment of $1 \mu \mathrm{g} / \mathrm{m}^{3}$ of $\mathrm{PM}_{2.5}$ [22].

Another co-benefit of reduced motorized traffic has been the decrease in road traffic incidents. A recent study from Spain, one of the countries most impacted by COVID-19 in Europe, indicated that emergency rooms reported an $80 \%$ reduction of traffic incidents between March and April 2020, compared to the same period in 2019 [23]. This has also been reported in the USA, where a recent study suggested a 50\% reduction in the number of crashes, including road injuries and fatalities, on California state highways during the "shelter-inplace" period (April-March 2020), compared to the same period in 2019 [16].

In contrast to the improvements in air quality and traffic safety, COVID-19 mitigation strategies have also been associated with negative externalities such as physical inactivity, home isolation, family violence, job instability, and mental health issues, among others [5, 24, 25]. COVID-19 mitigation strategies have limited physical activity, active transportation, and access to public spaces [5]. During the pandemic, more access to outdoor spaces and physical activity could help minimize the negative physical and mental impacts [26]. This poses challenges for urban settings where maintaining the mandated physical distance of $2 \mathrm{~m}(6 \mathrm{ft})$ is not always possible due to denser areas, low availability of public spaces, and the generally narrow width of sidewalks and bike lanes. In U.S. cities, for example, the required width for sidewalks is $1.5 \mathrm{~m}$ $(5 \mathrm{ft})$ and for bike lanes $2 \mathrm{~m}(6 \mathrm{ft})$ [27]. Another negative externality of COVID-19 mitigation strategies has been the reduction or closure of public transport options, impacting low-income communities, the elderly, and essential workers [28]. Responses to the COVID-19 pandemic should consider the safe provision of transport options, including public and active transportation, and micromobility (e.g., shared scooters and bikes) to ensure that people can continue to access essential services and support the mobility of essential workers.

A framework summarizing the links between COVID-19 mitigation strategies for the built environment and transport and how they affect health determinants and health outcomes is presented in Fig. 3. The framework describes how these mitigation strategies could reduce or increase related health determinants and outcomes. Mitigation strategies aim to reduce COVID-19 transmission with a subsequent reduction in 
Fig. 1 Global mobility trends from Apple Maps (a) and Google Maps (b) during the COVID-19 pandemic. *Apple Maps data include 63 countries. Baseline comparison of January 13, 2020. **Google Maps data include 131 countries and regions. Park: national parks, public beaches, marinas, dog parks, plazas, and public gardens. The baseline is defined as the average of the fiveweek period (January 3 to February 6, 2020)

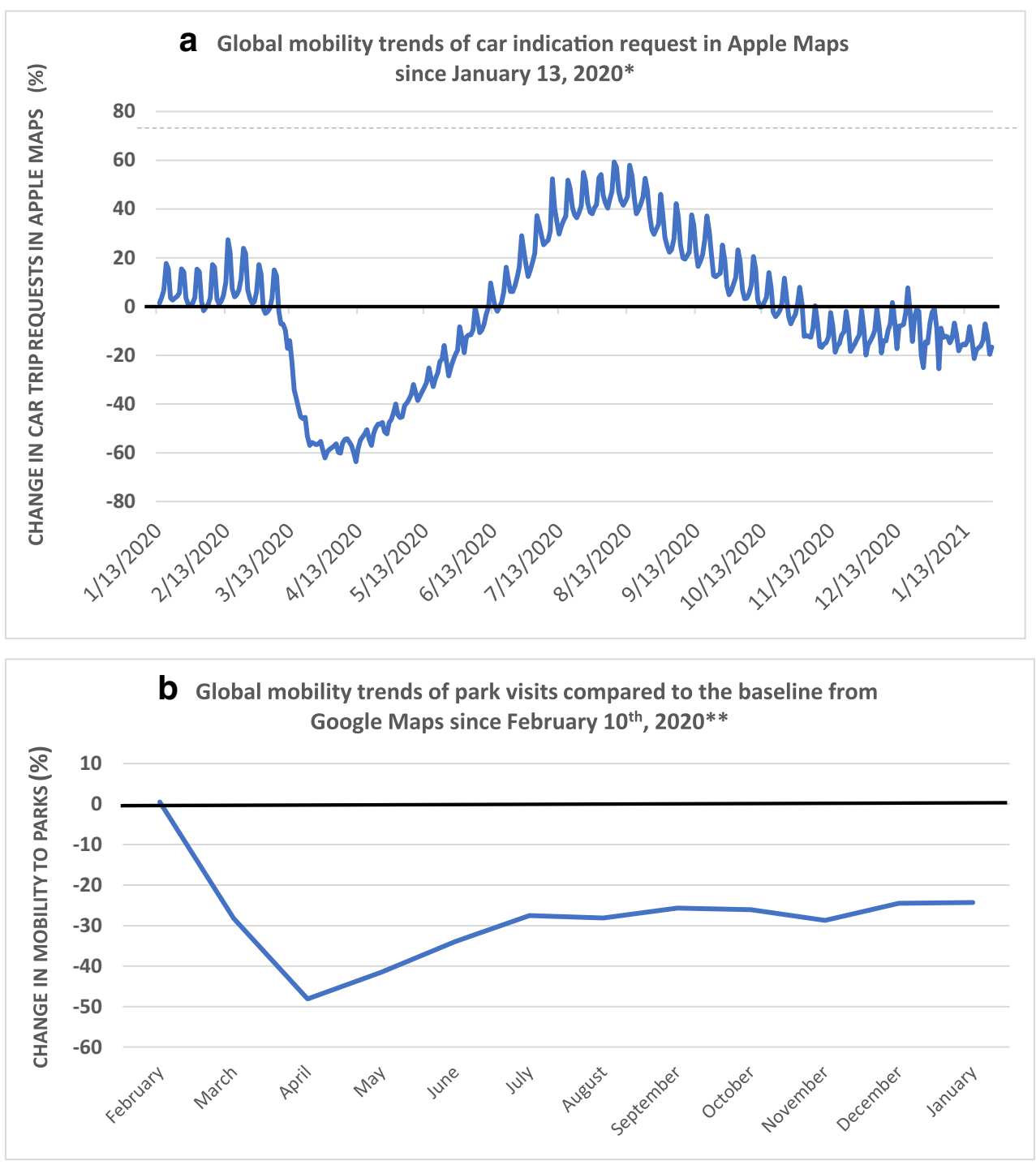

morbidity, mortality, and health economic impacts (Fig. 3). These strategies have also reduced other health risks (air and noise pollution and traffic incidents) that could result in better health outcomes (COVID-19 morbidity, mental disease, noncommunicable disease, road injuries, mortality, and healthrelated economic impacts) (Fig. 3). On the other hand, such mitigation strategies could also reduce physical activity and access to health services, worsening health outcomes (Fig. 3).

\section{COVID-19 Vulnerable Communities, Essential Workers, and Equity}

In the COVID-19 context, the term "vulnerable communities" refers to populations at a higher risk of severe illness from COVID-19. These communities are people aged 65 years and older, people who live in nursing homes (and long-term care facilities), and people of any age who have severe underlying medical conditions (e.g., chronic lung, kidney, or liver diseases, immunocompromised, diabetes, severe obesity, or severe heart conditions, among others) [11]. The U.S. Center for Disease Control and Prevention (CDC) recommends that this group should limit close contact with others, avoid crowds and non-essential travel, wash their hands often, and stay at home as much as possible [11]. While people with disabilities are not officially considered at high risk of severe illness from COVID-19, there is evidence that people with disabilities are more likely to have chronic health conditions compared to those without disabilities [29].

The U.S. government defines COVID-19 essential workers as those individuals working on critical infrastructures [30]. Such infrastructures are the communication sector, critical manufacturing, emergency services, energy, food and agriculture, healthcare and public health, transport systems, and water and wastewater systems, among others [30]. Current reports suggest that most essential occupations are low-wage, mostly composed of racial and ethnic minorities, and have a high share of workers below or near the poverty line [31, 32]. Prior to the pandemic, socially deprived communities were 


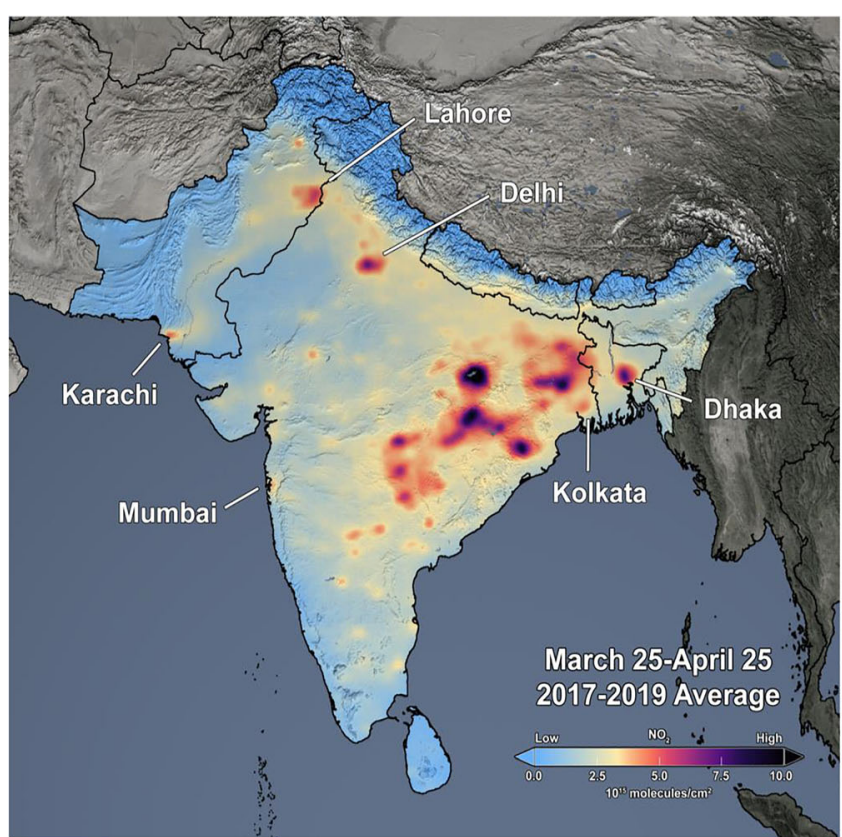

Fig. 2 Example of the air quality changes related to COVID-19 mitigation strategies in the Indian subcontinent (average tropospheric $\mathrm{NO}_{2}$ column in March 15-April 15, 2017-2019, and 2020). *Source:

already suffering from environmental health inequities (e.g., lack of access to public services and transport options or excess exposure to air and noise pollution) [33, 34]. In October 2020, a pilot study from New York University indicated that

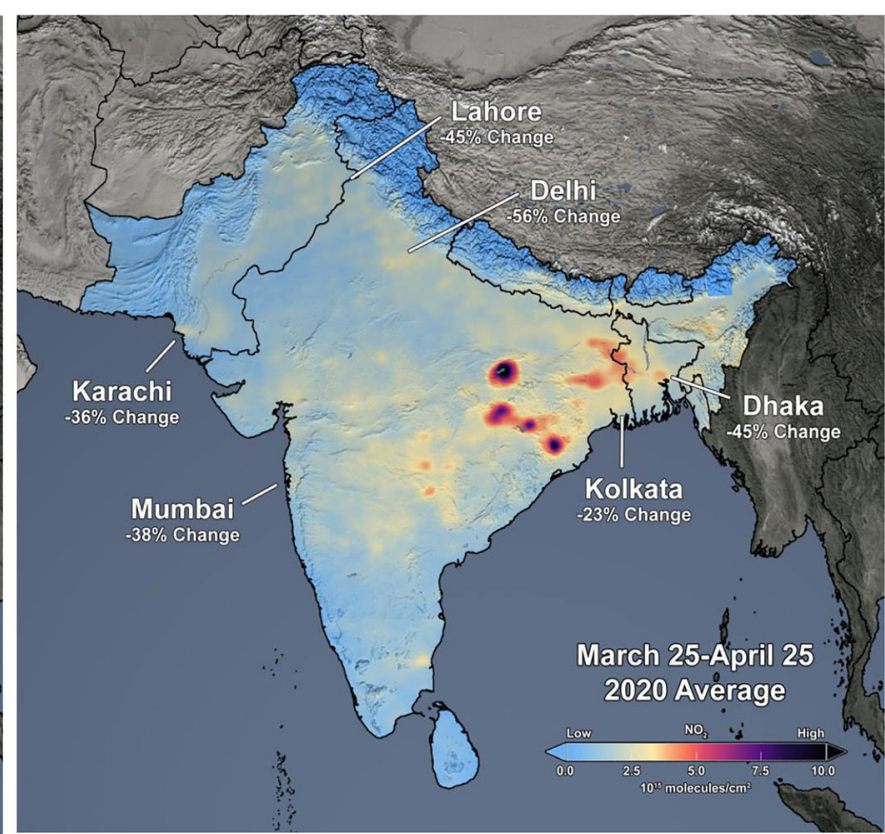

NASA. 2020. Reductions in nitrogen dioxide associated with decreased fossil fuel use resulting from COVID-19 mitigation. Sci Vis Stud. Available: https://svs.gsfc.nasa.gov/4810 (accessed 12 May 2020)

$24 \%$ of New York City (NYC) transit workers had a history of COVID-19 infection [35]. In January 2021, the NYC Metropolitan Transport Authority reported that 136 transit workers had died due to the virus [36]. Other U.S. cities have

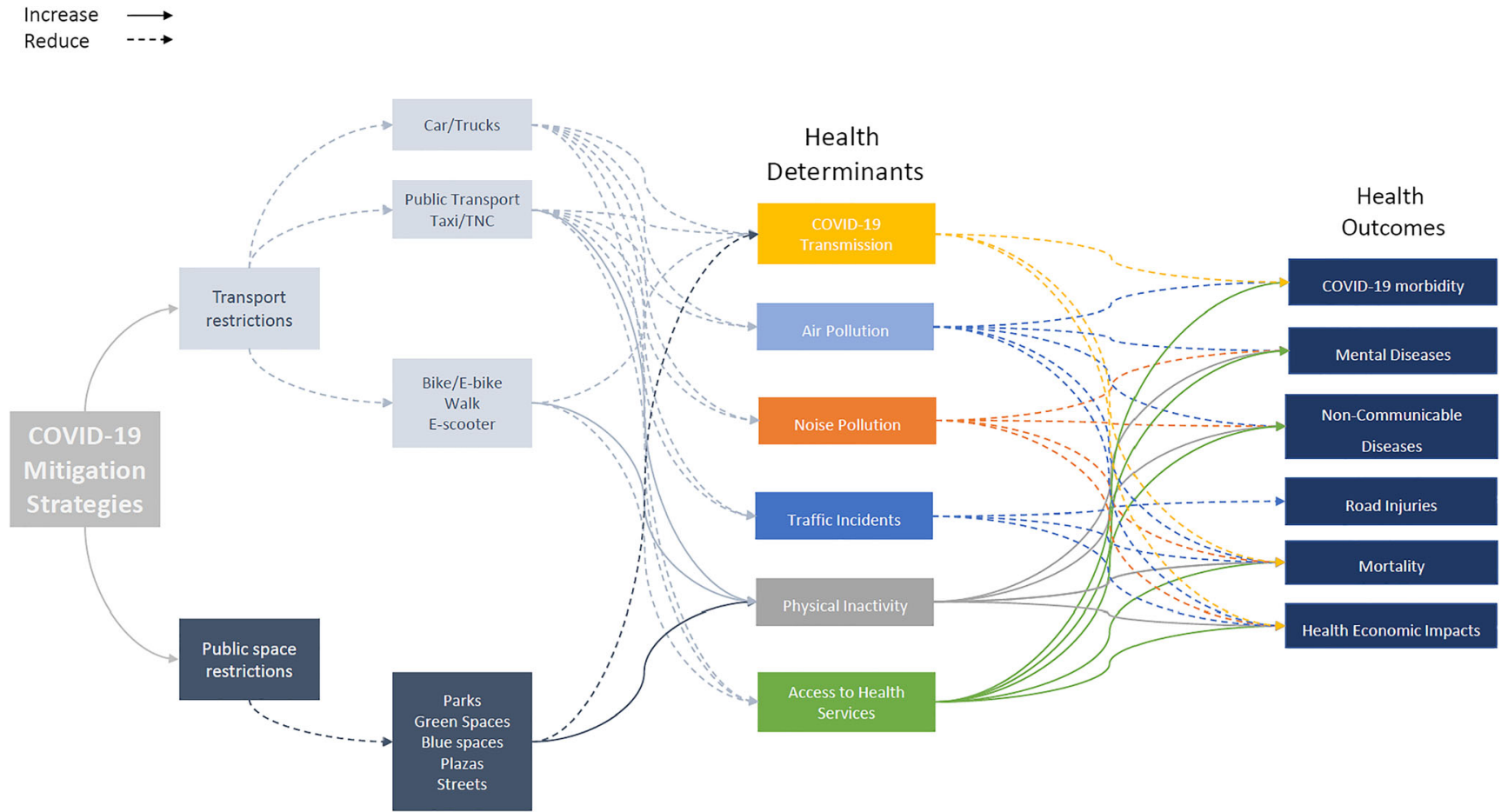

Fig. 3 Framework of COVID-19 mitigation strategies, urban health determinants, and outcomes. COVID-19 coronavirus disease 2019, TNC transport network companies (e.g., Uber/Lyft/Cabify), E-bike electric bikes, E-scooter electric scooters. Blue spaces refer to public beaches, lakes, and riversides, among others. Health service demand include COVID-19 test locations, hospital, and clinical services, among others 
also reported COVID-19 deaths among transit employees [37]. Specific considerations to improve urban services, the built environment, and mobility infrastructures should use an equity vision to adapt to the pandemic needs and provide a safe urban environment for vulnerable communities and essential workers in the short and long term.

\section{Urban Solutions for COVID-19 With a Long-Term Health Equity Vision}

Built environment and transport interventions can help support COVID-19 mitigation strategies while at the same time, improve air and noise quality, traffic safety, and physical activity opportunities (Fig. 4). A list of general urbanism interventions for COVID-19 and their links with health determinants and health outcomes is presented in Fig. 4. This figure highlights the potential for built environment and transport interventions to support COVID-19 mitigation strategies and improve environmental health determinants and health outcomes in the long term. In addition, such urban interventions should be used as a tool to prioritize essential workers, lowincome, and vulnerable communities, leading to reduced health inequities.
Several cities around the globe have been implementing different tactical urbanism interventions to support COVID19 mitigation strategies. Tactical urbanism refers to low-cost, temporary, and scalable interventions and policies intended to improve urban environments [38]. Examples of tactical urbanism are temporary bike lanes that do not require high-cost infrastructure and could be supported with temporary signaling and low-cost physical barriers (such as traffic cones). Although these tactical urbanism interventions are designed to be implemented in a temporary and low-cost approach, these interventions can be considered as pilot programs that could involve the community in selecting future permanent infrastructure. The COVID-19 pandemic offers a unique opportunity to test urban interventions that could reduce environmental health risks and inequities. Tactical urbanism interventions could be designed with a long-term vision to support a more permanent healthy urban design.

Below is a list of 10 key recommendations that could facilitate a systematic integration of short- and long-term COVID-19 urban interventions. This approach can help implement short-term mitigation strategies while at the same time, support long-term health equity. Recommendations marked with an asterisk $(*)$ refer to recommendations that apply during the pandemic, all others apply to a postpandemic context (an infographic of these recommendations

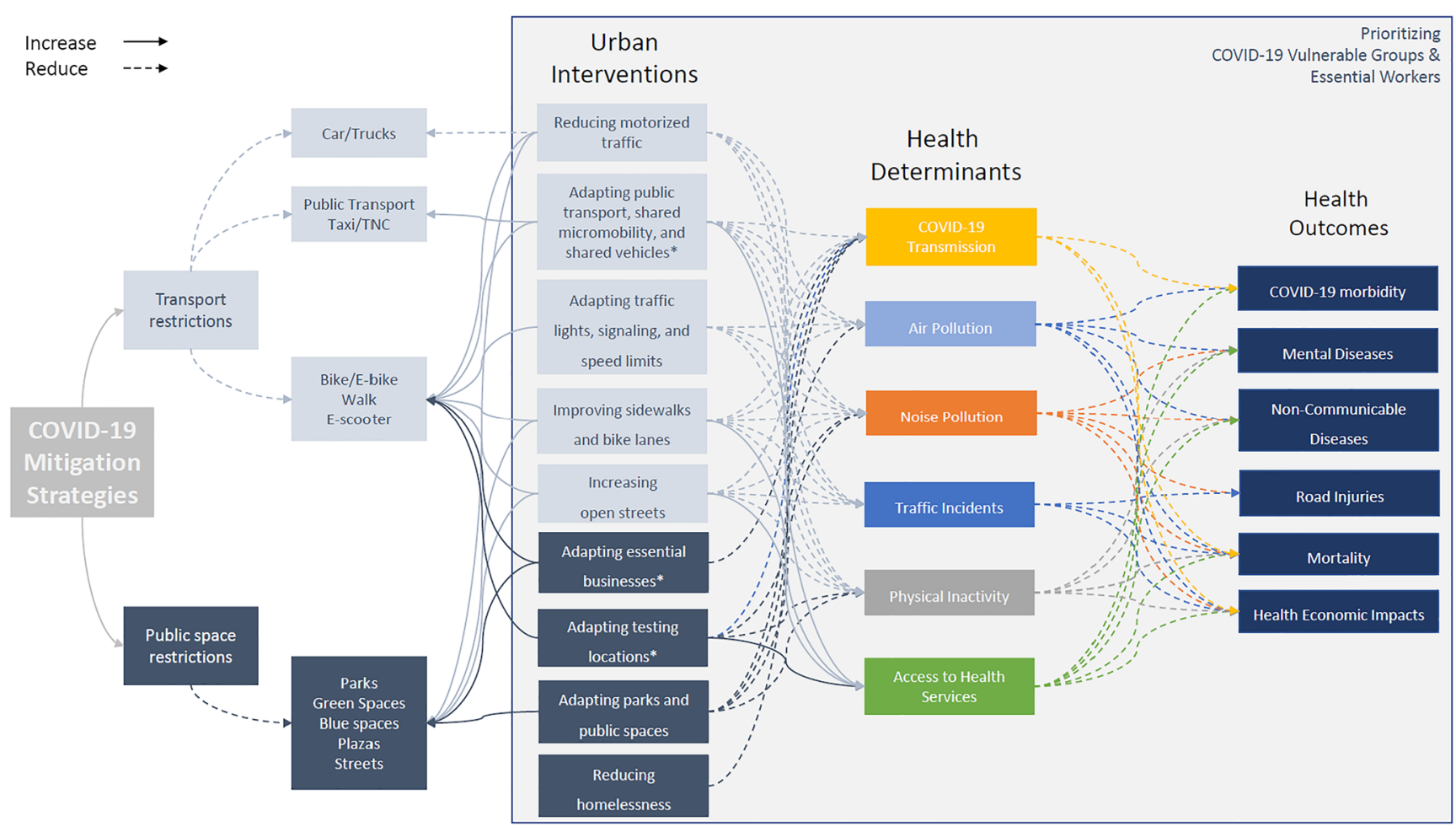

Fig. 4 Urban interventions in the context of COVID-19 mitigation strategies with long-term health equity vision. Recommendations marked with an asterisk refer to recommendations that apply during the pandemic; all others apply to a post-pandemic context. COVID-19 coronavirus disease 2019, TNC transport network companies (e.g.,
Uber/Lyft/Cabify), E-bike electric bikes, E-scooter electric scooters. Blue spaces refer to public beaches, lakes, and riversides, among others. Health service demand include COVID-19 test locations, hospital, and clinical services, among others 
is also included in English, Spanish, and Portuguese in the supplemental material):

\section{General COVID-19 tactical urbanism} recommendations: implement tactical urbanism interventions early*; discourage the use of public spaces and public transport for confirmed and suspected cases*; encourage physical distancing $(2 \mathrm{~m} / 6 \mathrm{ft})^{*}$; encourage physical activity; expand public open spaces; restrict access to public areas where physical distancing is not possible*; avoid large gatherings*; design interventions and prioritize implementation for vulnerable groups and essential workers; inform, promote, and enforce traffic safety regulations; and inform (clearly and accessibly) physical distancing orders and tactical urbanism changes (areas, uses, and schedules)*.

2. Sidewalks and bike lanes: promote walking and biking; expand sidewalks and bike lanes width, length, and connectivity to support physical distancing and traffic safety; expand sidewalks and bike lanes around parks, trails, and public spaces to reduce pressure on those spaces and encourage their use; implement protected bike lanes; expand bike parking; create pedestrian and cycling corridors and/or schedules for vulnerable populations (e.g., elderly and immunocompromised)*; use existing cycling and walking infrastructure proposals to guide the expansion; and encourage the use of bike helmets.

3. Open streets: implement everyday open streets; expand current open streets; enforce physical distance*; avoid large gatherings*; create user schedules favoring vulnerable populations*; and utilize open street traffic management protocols to support the expansion of new sidewalks and bike infrastructure.

4. Parks and public spaces: keep large public spaces (e.g., parks, open spaces, squares, plazas) open where physical distance can be maintained*; expand small open spaces; enforce physical distance*; avoid large gatherings*; expand bikes/e-scooter parking; create user schedules favoring vulnerable populations*; and prevent peak usage, informing and organizing users visits across different time windows.

5. Traffic lights, signaling, and speed limits: shift from actuated to fixed traffic signals; adjust traffic light timing favoring pedestrians and cyclists; provide updated, clear, and accessible tactical urbanism signaling; include stayat-home and physical distancing recommendations on traffic screens and signs*; and lower traffic speed limits.

6. Public transport, shared micromobility (e.g., bikes, scooters), and shared vehicles (e.g., taxi, Uber/Lyft): implement strict cleaning protocols and support efficient ventilation in vehicles and stations; implement backdoor boarding*; suspend in-person fare collection or implement waived fares*; distribute face coverings, protective glasses, gloves, and sanitizer to drivers and passengers*; limit passenger-driver interaction*; enforce physical distancing*; close every other row of seats*; reduce maximum occupancy* and increase service on crowding routes; install physical barriers (e.g., sneeze guards and partitions)*; create user schedules favoring vulnerable populations (e.g., elderly)*; support services for essential workers; promote bike-share; expand bike/e-scooter parking; encourage the use of bike/scooter helmets; integrate shared micromobility to public transit and bike lanes; and discourage or stop ridesharing (carpooling or vanpooling) and ridesplitting (e.g., Uber pool)*.

7. Motorized traffic: concentrate motorized transport in few streets and remove traffic lanes/parking spaces to support car-free streets, active transportation, and traffic safety, and when possible, concentrate freight traffic on main roads and at nighttime to improve traffic safety.

8. Essential businesses: designate bike shops as essential services; expand sidewalks for on-sidewalk queuing, restaurant seating, and outdoor markets*; avoid large gatherings*; enforce physical distance*; provide service to motorized and non-motorized transport; and establish dedicated delivering/loading zones.

9. Test and vaccination locations: provide multi-modal options to access test and vaccination sites and other health services*.

10. Homelessness: provide and adapt homeless shelters and services suited for physical distancing and COVID-19*.

\section{Urbanism After the Pandemic}

Before the pandemic, urban and transport planning was proposed as a key tool to promote environmental health and equity. During the pandemic, the current mobility trends and built environment needs have highlighted the benefits of urban and transport planning for public health. As countries in Asia, Europe, and North America start relaxing COVID-19 mitigation strategies to support their economies, urban mobility is showing mixed changes. Public transport is suffering from drop-in passengers and revenues across the globe. A study from China showed that 4 weeks after returning to work in the metropolitan area of Shenzhen, public transit use decreased by $34 \%$ compared to 2019 [39]. In the USA, a recent report estimated that transit agencies are suffering a financial impact of US\$26-US $\$ 40$ billion due to loss in transit fares and taxes and to COVID-19 mitigation costs, among others [40]. On the other hand, in March of 2020, cycling in Beijing grew by $150 \%$ [39]. Chinese bike-sharing companies have also reported an increase in longer trips ( $>3 \mathrm{~km}$ ) compared to 2019 , suggesting that longer trips, possibly made by motorized 
transport, have shifted to cycling [39]. In terms of motorized traffic, reports from the city of Wuhan, the COVID-19 epicenter, showed that in 2020, traffic levels decreased on average $20 \%$ compared to 2019 [41]. However, while most of those reductions occurred between January and May, by June, only two months after the Wuhan lockdown ended, congestion levels were similar to those in 2019 [41]. The pandemic's impact on the economy is another point of consideration for the future of urban mobility and urban planning. Specifically, the possible shift in car sales from more expensive vehicles (e.g., new cars, sport utility vehicles, and hybrid/electrics) to more affordable vehicles (e.g., used cars, compact/sedan, and gasoline) [42]. This scenario may translate into changes in traffic incidents and air and noise pollution. However, the pandemic may also lead to changes in teleworking practices, translating into commuting reductions. All these changes pose high uncertainties for the future of cities, making urban and transport planning more essential than ever in order to support public health.

\section{Conclusion}

Urbanism in the time of COVID-19 should be considered as a tool to support mitigation strategies. Particularly, tactical urbanism offers a set of low-cost, short-term interventions to mitigate the pandemic worldwide. Such interventions should be designed and implemented to prioritize vulnerable and low-income communities and essential workers. Until effective curative treatment or/and a vaccine is widely available, mitigation strategies can benefit from tactical urbanism alongside a coordinated governmental response, extensive testing, contact tracing, and quarantine. Post COVID-19, tested and effective tactical urbanism interventions could guide permanent and healthy equitable urban design.

Supplementary Information The online version contains supplementary material available at https://doi.org/10.1007/s40572-021-00307-7.

Code Availability Not applicable.

Author Contribution David Rojas-Rueda: conceptualization, data curation, formal analysis, investigation, methodology, visualization, writing - original draft. Emily Morales-Zamora: conceptualization, investigation, visualization, writing - review and editing.

\section{Compliance with Ethical Standards}

Ethics Approval Not applicable.

Consent to Participate Not applicable.
Consent for Publication Not applicable.

Conflict of Interest The authors declare that they have no competing interests.

\section{References}

1. WHO. Rolling updates on coronavirus disease (COVID-19): WHO characterizes COVID-19 as a pandemic. 2020 [cited 2020 Apr 30]. Available from: https://www.who.int/emergencies/diseases/novelcoronavirus-2019/events-as-they-happen.

2. Sekkides O. COVID-19 vaccines: the pandemic will not end overnight. The Lancet Microbe. 2021 [cited 2021 Jan 26];2:e1.

3. CDC. Frequently asked questions about COVID-19 vaccination. 2021 [cited 2021 Jan 26]. Available from: https://www.cdc.gov/ coronavirus/2019-ncov/vaccines/faq.html.

4. Mallapaty S. Scientists seek clues that COVID-vaccine rollouts are working. Nature. 2021 [cited 2021 Jan 26];504-5. Available from: https://media.nature.com/original/magazine-assets/d41586-02100140-w/d41586-021-00140-w.pdf.

5. Douglas M, Srinivasa VK, Martin T, Martin M, Gerry M. Mitigating the wider health effects of COVID-19 pandemic response OPEN ACCESS. BMJ. 2020 [cited 2020 May 20];369:16. Available from: https://www.bmj.com/content/bmj/369/bmj. m1557.full.pdf

6. Ebrahim SH, Ahmed QA, Gozzer E, Schlagenhauf P, Memish ZA. Covid-19 and community mitigation strategies in a pandemic. BMJ: BMJ Publishing Group; 2020.

7. Mccombs IdA, Kadelka IdC. A model-based evaluation of the efficacy of COVID-19 social distancing, testing and hospital triage policies. PLoS Comput Biol. 2020 [cited 2021 Jan 26];16. Available from: https://doi.org/10.1371/journal.pcbi.1008388

8. Pan A, Liu L, Wang C, Guo H, Hao X, Wang Q, et al. Association of public health interventions with the epidemiology of the COVID-19 outbreak in Wuhan, China, JAMA - J Am Med Assoc. American Medical Association; 2020

9. White House. National strategy for the COVID-19 response and pandemic preparedness. Washington DC; 2021.

10. The Lancet. Redefining vulnerability in the era of COVID-19. Lancet. Lancet Publishing Group; 2020. p. 1089.

11. CDC. Coronavirus Disease 2019 (COVID-19) | CDC [Internet]. 2020 [cited 2020 Apr 30]. Available from: https://www.cdc.gov/ coronavirus/2019-ncov/cases-updates/index.html.

12. CDC. COVID-19 in racial and ethnic minority groups. 2020 [cited $2020 \mathrm{Apr} 30]$. Available from: https://www.cdc.gov/coronavirus/ 2019-ncov/need-extra-precautions/racial-ethnic-minorities.html.

13. Apple. COVID-19-mobility report trends - Apple [Internet]. 2021 [cited 2021 Jan 16]. Available from: https://www.apple.com/ covid19/mobility.

14. Google. COVID-19 community mobility reports. 2021 [cited 2021 Jan 26]. Available from: https://www.google.com/covid19/ mobility/.

15. EEA. Air quality and COVID-19 - European Environment Agency. 2020 [cited 2020 Apr 30]. Available from: https://www. eea.europa.eu/themes/air/air-quality-and-covid19/air-quality-andcovid19

16. Shilling F, Waetjen D. Impact of COVID19 mitigation on numbers and costs of California traffic crashes Impact of COVID19 Mitigation on California Traffic Crashes. 2020. Available from: https://roadecology.ucdavis.edu/resources/stayathome-crashes.

17. CDC. Community mitigation. 2020. [cited 2020 May 13]. Available from: https://www.cdc.gov/coronavirus/2019-ncov/php/ open-america/community-mitigation.html. 
18. Prem K, Liu Y, Russell TW, Kucharski AJ, Eggo RM, Davies N, et al. The effect of control strategies to reduce social mixing on outcomes of the COVID-19 epidemic in Wuhan, China: a modelling study. Lancet Public Heal. Elsevier Ltd. 2020;5:e261-70.

19. Bauwens M, Compernolle S, Stavrakou T, Müller J -F., Gent J, Eskes $\mathrm{H}$, et al. Impact of coronavirus outbreak on $\mathrm{NO}_{2}$ pollution assessed using TROPOMI and OMI observations. Geophys Res Lett. John Wiley \& Sons, Ltd; 2020 [cited 2020 May 19]; Available from: https://doi.org/10.1029/2020GL087978

20. Shi X, Brasseur GP. The response in air quality to the reduction of Chinese economic activities during the COVID-19 outbreak. Geophys Res Lett. John Wiley \& Sons, Ltd; 2020 [cited 2020 May 19]; Available from: https://doi.org/10.1029/2020GL088070

21. NASA. Reductions in nitrogen dioxide associated with decreased fossil fuel use resulting from COVID-19 mitigation. Sci. Vis. Stud. 2020 [cited 2020 May 12]. Available from: https://svs.gsfc.nasa. gov/4810.

22. Wu X, Nethery RC, Sabath BM, Braun D, Dominici F. Exposure to air pollution and COVID-19 mortality in the United States. medRxiv. Cold Spring Harbor Laboratory Press. 2020;2020(04): 05.20054502 .

23. Nuñez JH, Sallent A, Lakhani K, Guerra-Farfan E, Vidal N, Ekhtiari S, et al. Impact of the COVID-19 pandemic on an emergency traumatology service: experience at a tertiary trauma centre in Spain. Injury. Elsevier; 2020 [cited 2020 May 19]; Available from: https://linkinghub.elsevier.com/retrieve/pii/ S0020138320304228.

24. Pinto AJ, Dunstan DW, Owen N, Bonfá E, Gualano B. Combating physical inactivity during the COVID-19 pandemic. Nat. Rev. Rheumatol. Nature Research; 2020. p. 1-2.

25. WHO. Mental health and psychosocial considerations during the COVID-19 outbreak. 2020.

26. Jiménez-Pavón D, Carbonell-Baeza A, Lavie CJ. Physical exercise as therapy to fight against the mental and physical consequences of COVID-19 quarantine: special focus in older people. Prog Cardiovasc Dis. W.B. Saunders; 2020.

27. FHWA. Course on bicycle and pedestrian transportation instructor's guide. 2013.

28. Hale T, Webster S, Petherick A, Phillips T, Kir B. Public transport closures during the COVID-19 pandemic, May 19, 2020. Oxford COVID-19 Gov. Response Tracker, Blavatnik Sch. Gov. 2020 [cited 2020 May 19]. Available from: https://ourworldindata.org/ grapher/public-transport-covid.

29. Krahn GL, Walker DK, Correa-De-Araujo R. Persons with disabilities as an unrecognized health disparity population. Am J Public Health. American Public Health Association Inc.; 2015;105:S198_ 206.

30. CISA. Identifying critical infrastructure during COVID-19. U.S. Cybersecurity Infrastruct. Secur. Agency. 2020 [cited 2020 May 13]. Available from: https://www.cisa.gov/identifyingcritical-infrastructure-during-covid-19.
31. PPIC. Essential workers and COVID-19 - Public Policy Institute of California. Public Policy Inst. Calif. 2020 [cited 2020 May 13]. Available from: https://www.ppic.org/blog/essential-workers-andcovid-19/.

32. Pittalwala I. Social implications of COVID-19. Univ. Calif. Riverside. 2020 [cited 2020 May 13]. Available from: https:// insideucr.ucr.edu/stories/2020/04/16/social-implications-covid-19

33. Weinstein JN, Geller A, Negussie Y, Baciu A. Communities in action: pathways to health equity. Communities Action Pathways to Heal. Equity. National Academies Press; 2017.

34. Gouveia N. Addressing environmental health inequalities. Int J Environ Res Public Health. MDPI AG; 2016

35. Gershon R. Nearly a quarter of New York City transit workers report having had COVID-19. 2020 [cited 2021 Jan 26]. Available from: https://www.nyu.edu/about/news-publications/ news/2020/october/transit-workers-covid-pilot-study.html.

36. Guse C. NYC MTA launches subway memorial for 136 workers killed by COVID - New York Daily News. NY Dly. News. 2021 [cited 2021 Jan 26]. Available from: https://www.nydailynews. com/coronavirus/ny-subway-memorial-covid-mta-20210125146e3egndzerpfgjlnejeqf75i-story.html.

37. Beckett L. Revealed: nearly 100 US transit workers have died of Covid-19 amid lack of basic protections | Coronavirus outbreak | The Guardian. Guard. 2020 [cited 2020 May 13]. Available from: https://www.theguardian.com/world/2020/apr/20/us-bus-driverslack-life-saving-basic-protections-transit-worker-deathscoronavirus.

38. Lydon M, Garcia A. Tactical urbanism: short-term action for longterm change. Tactical Urban. Short-Term Action Long-Term Chang. Island Press-Center for Resource Economics; 2015.

39. ITDP. Post-pandemic, Chinese cities gradually reopen transport networks - Institute for Transportation and Development Policy. Transp Matters 2020 [cited 2020 May 13]. Available from: https://www.itdp.org/2020/03/26/post-pandemic-chinese-citiesgradually-reopen-transport-networks/.

40. TransitCenter. Estimated financial impact of COVID-19 on U.S. transit agencies: \$26-\$40 billion annually. Policy. 2020 [cited 2020 May 20]. Available from: https://transitcenter.org/estimatedfinancial-impact-of-covid-19-on-u-s-transit-agencies-26-38billion-annually/.

41. TomTom. Wuhan traffic report | TomTom Traffic Index. 2021 [cited 2021 Jan 26]. Available from: https://www.tomtom.com/en_gb/ traffic-index/wuhan-traffic/.

42. McKinsey. The new normal: impact of COVID-19 on mobility solutions. 2020 [cited 2020 May 20]. Available from: https:// www.mckinsey.com/industries/automotive-and-assembly/ourinsights/the-impact-of-covid-19-on-future-mobility-solutions.

Publisher's Note Springer Nature remains neutral with regard to jurisdictional claims in published maps and institutional affiliations. 